\title{
Downregulation of DcR3 sensitizes hepatocellular carcinoma cells to TRAIL-induced apoptosis
}

This article was published in the following Dove Press journal:

OncoTargets and Therapy

18 January 2017

Number of times this article has been viewed

\author{
Chaojie Liang* \\ Yingchen $\mathrm{Xu}^{*}$ \\ Guangming Li \\ Tuanjie Zhao \\ Feng Xia \\ Guanqun Li \\ Dongxin Zhang \\ jixiang $\mathrm{Wu}$
}

Department of General Surgery,

Beijing Tongren Hospital, Capital

Medical University, Beijing,

People's Republic of China

*These authors contributed equally to this work
Correspondence: Jixiang Wu;

Guangming Li

Department of General Surgery, Beijing

Tongren Hospital, Capital Medical

University, No 2 Chongwenmennei

Street, Dongcheng, Beijing 100730,

People's Republic of China

$\mathrm{Tel}+86$ I38 010151 I8;

+86 I35 0 II 22244

Email trwujixiang2016@।26.com;

liguangming2016@I26.com

\begin{abstract}
Decoy receptor 3 (DcR3) has been recently described as an antiapoptosis and prometastasis factor since it can competitively bind to FasL, TL1A, and LIGHT, and it is highly expressed in many malignant tumors. Downregulation of DcR3 can promote tumor cell apoptosis and inhibit metastasis. A previous study demonstrated that reduction of DcR3 could induce tumor necrosis factor-related apoptosis-inducing ligand (TRAIL)-mediated apoptosis in pancreatic cancer cells. However, whether such an effect is seen in hepatocellular carcinoma (HCC) remains to be explored. This study was designed to investigate the sensitivity of HCC cells to TRAIL after silencing DcR3, and this was done by evaluating the expression of DcR3 in HCC cells and the effect on TRAIL-mediated apoptosis after downregulation of DcR3. Our data showed that DcR3 was highly expressed in HepG2, BEL-7402, Hep3B, Huh-7, MHCC97H, and SMCC7721 cell lines compared with normal liver cell line LO-2. Both HepG2 and BEL-7402 were tolerant to TRAIL-mediated apoptosis, and the tolerance was negatively correlated to the expression of DcR3. Silencing of DcR3 with shRNA and treatment with TRAIL induced obvious apoptosis in HepG2 and BEL-7402, with more cancer cells found in the G1 phase. SiDcR3 combined with TRAIL could induce activation of caspases-3, -8 , and -9 , raise the expression of the apoptotic protein Bax, and reduce the expression of antiapoptotic proteins (Bcl-2, Mcl-1, Bcl-XL, IAP-2, and survivin). Caspase-8 inhibitor Ac-IETD-CHO significantly decreased the activation of caspase cascade, indicating that the extrinsic pathway may have a vital role in the apoptotic events induced by SiDcR3/TRAIL. Furthermore, our results showed that the TRAIL death receptor 5 (DR5) was upregulated and that DR5 neutralizing antibody abrogated the effect of SiDcR3. Our results demonstrated that downregulation of DcR3 could enhance TRAIL-mediated apoptosis in HCC through the death receptor pathway. In the future, this might be useful as a clinical treatment method of liver cancer.
\end{abstract}

Keywords: apoptosis, DcR3, TRAIL, HCC, DR5, caspase-8

\section{Introduction}

Hepatocellular carcinoma (HCC) is one of the most common malignant tumors in the world. The incidence of HCC ranks sixth among all cancers with approximately 600,000 people affected. ${ }^{1} \mathrm{HCC}$ is among a group of tumors that have the highest mortality rate. ${ }^{1}$ Since the early symptoms of liver cancer are not obvious, early diagnosis is difficult. When diagnosed, HCC is almost at the intermediate or the advanced stage. Clinical treatments for liver cancer include liver resection, liver transplantation, chemotherapy, and radiotherapy. For liver cancer, the rate of 5 -year survival is very low because of poor response to various kinds of treatments. Development of new cancer treatments is gradually becoming a research hotspot in recent years..$^{2-5}$ 
Tumor necrosis factor (TNF)-related apoptosis-inducing ligand (TRAIL), a member of the TNF superfamily, was first cloned from human peripheral blood and heart cDNA library. ${ }^{6}$ Similar to other TNFs, when bound with its receptor, TRAIL can induce tumor cell apoptosis. ${ }^{78}$ So far, five receptors, DR4, DR5, Decoy receptor 1 (DcR1), DcR2, and OPG, have been found. ${ }^{9-12}$ Binding of DR4 and DR5 to TRAIL activates the death receptor pathway, produces DISC, and activates caspase-8, resulting in the activation of caspase-3, caspase- 6 , and caspase- 7 , inducing death pathways into mitochondria, and further activating the Bcl-2 family and other molecules. This process induces apoptosis. ${ }^{13}$ The TRAIL pathway kills tumor cells but is harmless to normal cells, which makes it a more promising treatment target. ${ }^{14}$ However, many tumor cells show tolerance to TRAIL, ${ }^{15}$ and liver cancer is no exception ${ }^{16}$ as there is sufficient evidence showing that various liver cancer cell lines have different degrees of tolerance to TRAIL. Therefore, reducing the tolerance of TRAIL will be of great help to the development of new treatments for HCC.

DcR3, a member of the soluble TNF receptor (TNFR) superfamily, sharing a similar sequence with OPG, TNF2, and Fas, can competitively bind to FasL, TL1A, and LIGHT, inhibit apoptosis, modulate immune function, and induce angiogenesis. ${ }^{17-19}$ DcR3 has been found to be highly expressed in many malignant tumors. ${ }^{20-23}$ Silencing of DcR3 can affect the proliferation, invasion, and metastasis ability of tumor cells and sensitize tumor cells to Fas-mediated apoptosis. ${ }^{24,25}$ A previous study has reported that reduction of DcR3 can increase the sensitivity of pancreatic cancer cells to TRAIL-mediated apoptosis. ${ }^{25}$ However, DcR3 has not been studied in HCC cell lines. The purpose of the present study was to investigate whether reduction of DcR3 can potentiate TRAIL-mediated apoptosis in HCC cells and to explore the molecular mechanisms of this process.

\section{Materials and methods Cell culture}

Human HCC cell lines HepG2, Huh-7, and BEL-7402 were purchased from the Cell Bank of Shanghai Institute of Biochemistry and Cell Biology (Shanghai, People's Republic of China). MHCC97H and SMCC7721 were purchased from the cell bank of Zhongshan Hospital, Fudan University (Shanghai, People's Republic of China). Hep3B and LO-2 were purchased from the Cancer Hospital of the Chinese Academy of Medical Sciences (Beijing, People's Republic of China). Cells were maintained in Dulbecco's Modified Eagle's Medium supplemented with 10\% fetal bovine serum
(Gibco, Waltham, MA, USA), $100 \mathrm{U} / \mathrm{mL}$ penicillin, and $100 \mu \mathrm{g} / \mathrm{mL}$ streptomycin (Invitrogen, Carlsbad, CA, USA) in $5 \% \mathrm{CO}_{2}$ at $37^{\circ} \mathrm{C}$.

\section{Antibodies and reagents}

DcR3 polyclonal antibody, recombinant human TRAIL (rhTRAIL), and neutralizing antibodies against TRAIL-R1 (DR4) and TRAIL-R2 (DR5) were purchased from R\&D Systems (Minneapolis, MN, USA). Rat monoclonal antibodies against Mcl-1, Bcl-XL, Bax, survivin, IAP-2, DR4, DR5, and GAPDH were purchased from Abcam (Shanghai, People's Republic of China). Ac-DEVD-AMC, Ac-IETDAFC, Ac-LEHD-AMC, caspase-8 inhibitor IETD-CHO, and caspase-9 inhibitor LEHD-CMK were purchased from BD Biosciences (San Jose, CA, USA).

\section{Lentiviral shRNA-mediated DcR3 silencing}

Target shDcR3 was cloned into pLKO.1.-CMV vector. Target and nontarget vectors were packaged into lentiviral particles by BIOREE (Beijing, People's Republic of China). Each particle was transduced into appropriate human liver cancer lines and selected by antibiotic resistance. These clones were screened using quantitative real-time polymerase chain reaction (PCR) for DcR3 expression, and the results were confirmed by enzyme-linked immunosorbent assay (ELISA).

\section{ELISA and reverse transcriptase PCR (RT-PCR)}

Supernatants of cell culture medium were collected and analyzed by sandwich ELISA using DcR3 ELISA Kit (R\&D Systems) according to the manufacturer's instructions. For DcR3 messenger RNA level, total RNA was extracted with Trizol reagent (Invitrogen, Beijing, People's Republic of China) according to the manufacturer's instructions. cDNA was synthesized from total RNA with Goscript ${ }^{\mathrm{TM}}$ Reverse Transcription System (Promega, Beijing, People's Republic of China) and random hexamers. PCR was performed using Bio-Rad PCR System (BIORAD, Beijing, People's Republic of China). Relative quantification was determined by normalization to the amount of actin. Primers used for real-time PCR, 5'-CTCTTCCTCCCATGACAC-3' and $5^{\prime}$-CTGGAAAGCCACAAAGTC-3' for DcR3 (112 bp), and $5^{\prime}$-ccaaccgcgagaagatga- $3^{\prime}$ and $5^{\prime}$-ccagaggcgtacagggatag- $3^{\prime}$ for actin (97 bp), were designed by Primer Express 3.0 and synthesized by Invitrogen, Waltham, MA, USA. PCRamplified products were examined by electrophoresis on $2 \%$ agarose gel with ethidium bromide staining. 


\section{Cell viability assay}

The effect of TRAIL on HCC cell viability was analyzed using Cell Counting Kit-8 (CCK-8) (Dojindo, Kumamoto, Japan). Cells were incubated in different concentrations of TRAIL $(0,25,50$, and $100 \mathrm{ng} / \mathrm{mL})$ for $24 \mathrm{~h}$, then CCK- 8 was added and incubated at $37^{\circ} \mathrm{C}$ for $2 \mathrm{~h}$. Ultraviolet spectrophotometer was used to measure the absorbance of each treatment group at $450 \mathrm{~nm}$. Cell viability index was calculated: (experiment optical density $(\mathrm{OD})_{450}$-blank $\left.\mathrm{OD}_{450}\right) /\left(\right.$ control $\mathrm{OD}_{450}-$ blank $\left.\mathrm{OD}_{450}\right) \times 100 \%$.

\section{Cell cycle and apoptosis analysis}

Apoptotic changes were detected by fluorescein isothiocyanate (FITC)-Annexin V staining. Propidium iodide (PI) was used to discriminate between apoptotic and necrotic cells among the Annexin V-positive cells.

Cells were treated with TRAIL $(100 \mathrm{ng} / \mathrm{mL})$ or vehicle dimethyl sulfoxide (DMSO) for $24 \mathrm{~h}$ and washed and resuspended in $100 \mu \mathrm{L}$ binding buffer solution (Annexin-VFITC Kit, Cwbiotech, Beijing, People's Republic of China). Annexin V-FITC $(5 \mu \mathrm{L})$ and PI $(5 \mu \mathrm{L})$ were then added to the cell suspension for a 10-min incubation followed by fluorescence-activated cell sorting (FACS) analysis. For cell cycle analysis, cells were harvested and fixed using $75 \%$ ethanol overnight at $4^{\circ} \mathrm{C}$. Cells were then incubated with RNase A for $30 \mathrm{~min}$ at $37^{\circ} \mathrm{C}$ and stained with PI. Cell cycle was determined by flow cytometry.

\section{Caspase assays}

Substrates Ac-DEVD-AMC, Ac-IETD-AFC, and Ac-LEHDAMC were used to assess the activities of caspase-3, caspase-8, and caspase- 9 in protein extractions using a fluorimeter according to the manufacturer's instructions (BD Biosciences).

\section{Western blotting}

Cells were lysed using radioimmunoprecipitation assay lysis buffer (Beyotime Institute of Biotechnology, Haimen, People's Republic of China), and the protein concentrations were quantified using the BCA Kit (Cwbiotech, Beijing, People's Republic of China). Equal amounts of proteins $(40 \mu \mathrm{g})$ were separated by sodium dodecyl sulfate-polyacrylamide gel electrophoresis and then transferred to polyvinylidene difluoride membranes (Millipore, Bedford, MA, USA). The membranes were blocked with 5\% nonfat milk at room temperature for $1 \mathrm{~h}$ and then incubated with individual primary antibody overnight at $4^{\circ} \mathrm{C}$. After extensive washes, the secondary antibody (Abcam, Beijing,
People's Republic of China) was added to the system. Finally, immunoreactive protein bands were determined using the enhanced chemiluminescence system (Thermo Fisher Scientific, Waltham, MA, USA).

\section{Treatment of cells with neutralizing antibodies}

HepG2-LV-SiDcR3 cells were treated with neutralizing antibodies of DR4 and DR5 for $1 \mathrm{~h}$ and incubated with TRAIL $(100 \mathrm{ng} / \mathrm{mL})$ for $24 \mathrm{~h}$.

\section{Statistical analysis}

All data are expressed as mean \pm standard deviation. Oneway analysis of variance test or unpaired Student's $t$-test was used to perform comparison in all groups. Differences were considered significant at $P<0.05$. Three independent experiments were performed for each treatment. All statistical analyses were conducted using Graphpad Prism 6.0 (Graphpad Software, La Jolla, CA, USA).

\section{Results \\ Expression of DcR3- and TRAIL-mediated apoptosis}

The expression of DcR3 was measured using six liver cancer cell lines, HepG2, Huh-7, BEL-7402, Hep3B, MHCC97H, and SMCC7721 and human embryonic liver cell line LO-2. As shown in Figure 1A, ELISA and RT-PCR confirmed that expression of DcR3 increased to a different extent in six liver cancer cell lines compared with the normal liver cell line LO-2; HepG2 had the highest increase and BEL-7402 had the lowest $(P<0.05)$. We chose HepG2 and BEL-7402 for further investigation. Cells were incubated in TRAIL $100 \mathrm{ng} / \mathrm{mL}$ for $24 \mathrm{~h}$, as shown in Figure 1B. Apoptosis analysis with Annexin V/PI staining revealed that the degree of apoptosis of HepG2 was lower than that of BEL-7402. According to the findings of a previous study, ${ }^{26}$ both of the HCC cell lines are tolerant to TRAIL. In this analysis, we found that the sensitivity of TRAIL-mediated apoptosis was negatively correlated to the expression of DcR3. Therefore, we hypothesized that DcR3 is a key factor of the resistance of liver cancer cell lines to TRAIL.

\section{Reduced DcR3 expression could enhance the effects of TRAIL on apoptosis}

Stable DcR3-knockdown HepG2 and BEL-7402 cell lines, ie, HepG2-LV-SiDcR3 and BEL-7402-LV-SiDcR3, were established to investigate whether downregulation of DcR3 could enhance the sensitivity of HCC cells toward TRAIL- 
A
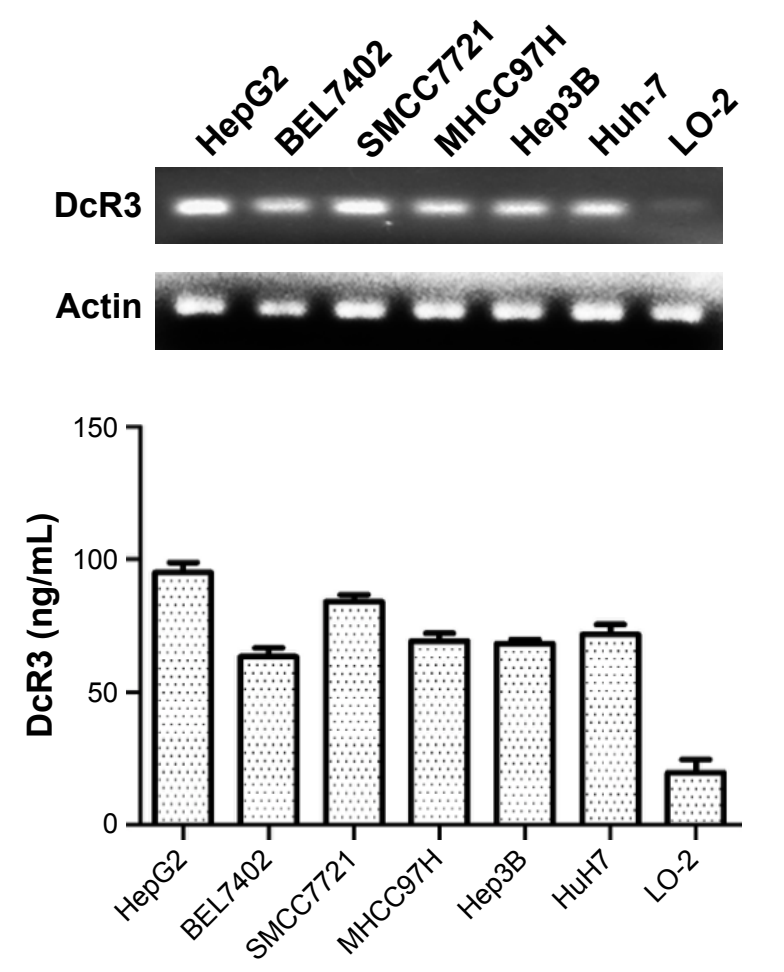

B DMSO

Plot PO2, gated on

P01, R1

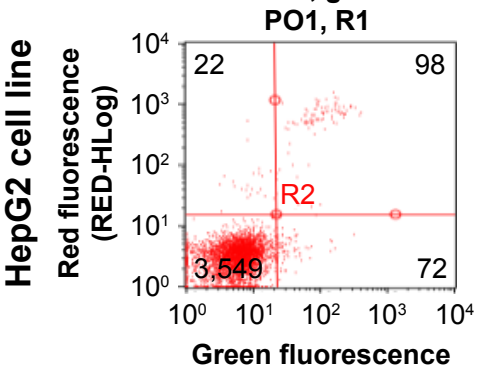

(GRN-HLog)

Plot PO2, gated on

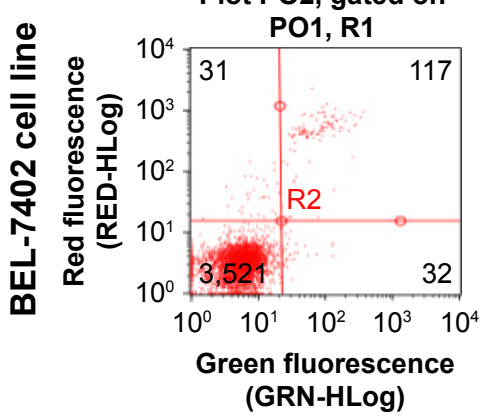

TRAIL

Plot PO2, gated on P01, R1

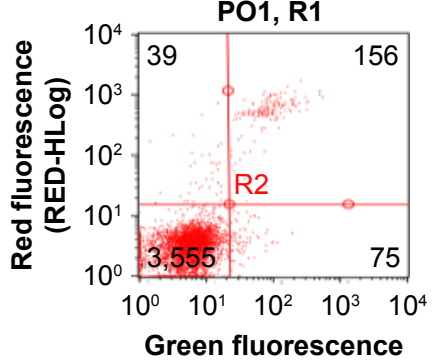

(GRN-HLog)

Plot PO2, gated on P01, R1

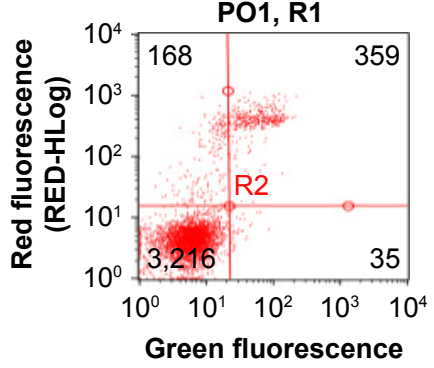

(GRN-HLog)

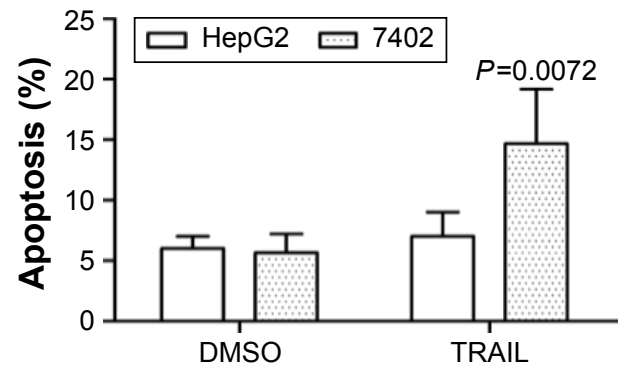

Figure I Expression of DcR3 in hepatocellular carcinoma cell lines and sensitivity to TRAIL for HepG2 and BEL-7402.

Notes: (A) The expression of DcR3 in different hepatocellular carcinoma cells was quantified by qPCR and measured by ELISA. The differences among cell lines were significant $(P<0.01)$. (B) The sensitivity of HepG2 and BEL-7402 cells to TRAIL $(100 \mathrm{ng} / \mathrm{mL})$ was measured by Annexin V. TRAlL had no significant effect on HepG2 $(P>0.05)$, but the apoptosis of BEL-7402 increased. DMSO was used as control. Data in the bar graphs represent the mean \pm SD of three repeated experiments.

Abbreviations: DcR, decoy receptor; ELISA, enzyme-linked immunosorbent assay; qPCR, quantitative polymerase chain reaction; SD, standard deviation; TRAIL, tumor-necrosis factor-related apoptosis-inducing ligand; DMSO, dimethyl sulfoxide.

mediated apoptosis. As show in Figure 2A, RT-PCR and ELISA confirmed that DcR3 expression markedly declined in HepG2-LV-SiDcR3 and BEL-7402-LV-SiDcR3.

HCC cell lines treated with different levels of TRAIL $(0,25,50,100 \mathrm{ng} / \mathrm{mL})$ for $24 \mathrm{~h}$ were used to measure cell viability by CCK-8 assay. As showed in Figure 3B, cell viability of HepG2-LV-SiDcR3 and BEL-7402-LV-SiDcR3 was restrained significantly $(P<0.05)$ in a dose-dependent manner compared with control cells. Annexin-V/PI assay was used to measure apoptosis in HepG2 cell lines treated with TRAIL (100 ng/mL, 24 h); DMSO was used as control. Data demonstrated that apoptosis increased significantly (Figure 2B) in HepG2-LV-SiDcR3/TRAIL $(P<0.05)$. Cell cycle was measured by flow cytometry; compared with HepG2-LV-NC/TRAIL, a clear increase in G0/G1 phase cells was observed in HepG2-LV-SiDcR3/TRAIL. These results suggested that knockdown of DcR3 expression could enhance the apoptotic effects of TRAIL on HCC cells.

\section{SiDcR3 combined with TRAIL activated extrinsic and intrinsic signaling pathways}

To explore the mechanism of cell death involved in SiDcR3/ TRAIL, we first investigated whether the synergistic effect of DcR3/TRAIL was due to the increase of caspase activity. The activities of caspases-3, -8 , and -9 increased obviously in HepG2-LV-SiDcR3/TRAIL (Figure 4) compared with the treatment of SiDcR3 or TRAIL (100 ng/mL) alone. This suggested that downregulation of DcR3 combined with TRAIL could activate both extrinsic and intrinsic signaling pathways. Then, we explored the role of caspase- 8 and caspase- 9 in SiDcR3/TRAIL-caspase activation. HepG2-LV-NC and HepG2-LV-SiDcR3 were incubated in the presence or 
A

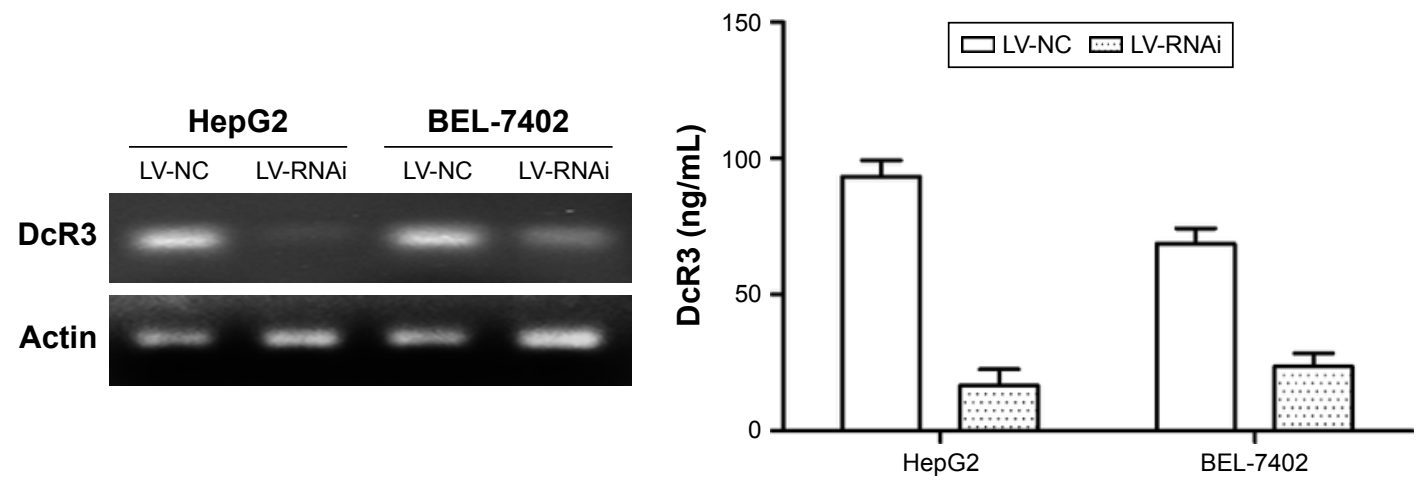

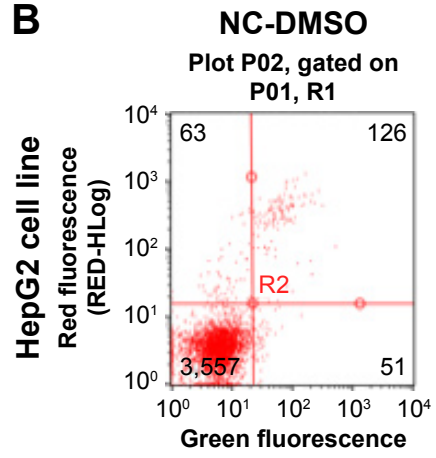

(GRN-HLog)

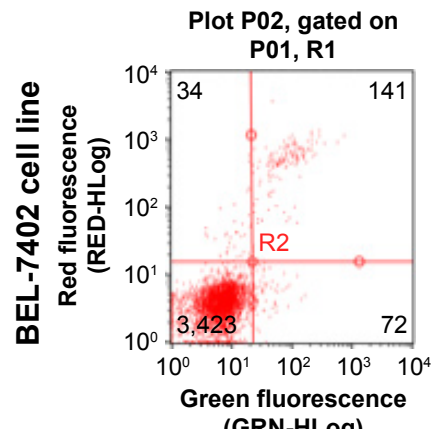

(GRN-HLog)

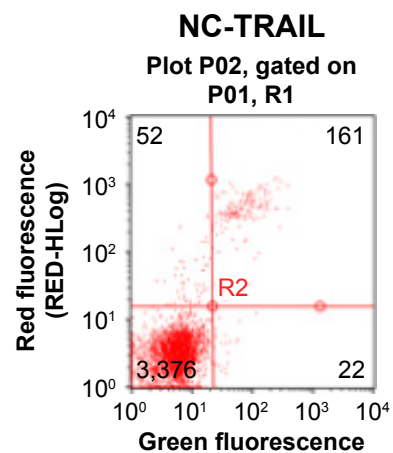

(GRN-HLog)

Plot P02, gated on

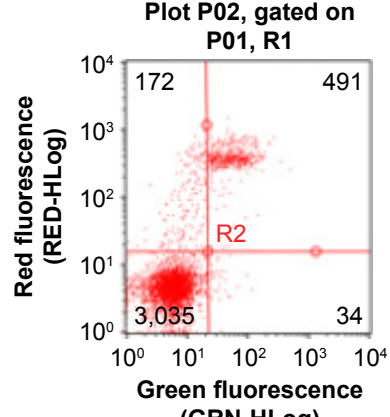

(GRN-HLog)

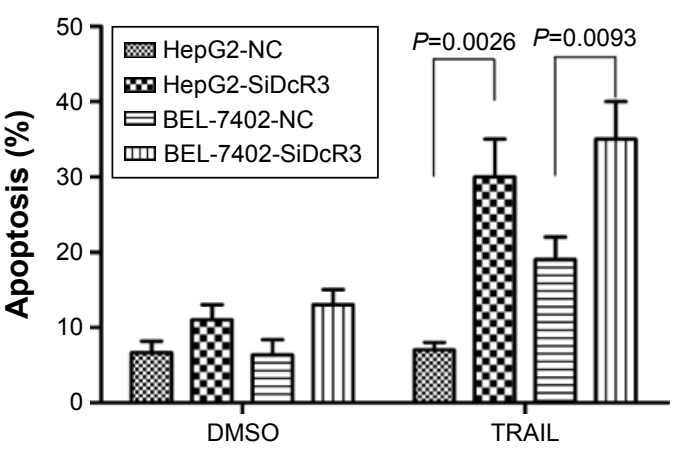

SiDcR3-TRAIL

Plot P02, gated on P01, R1

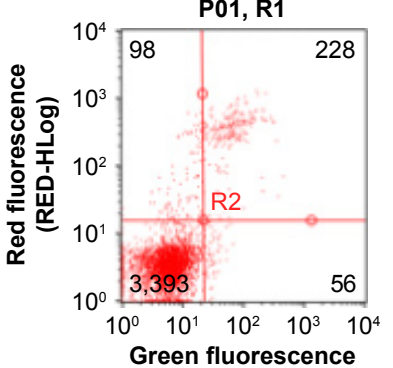

(GRN-HLog)

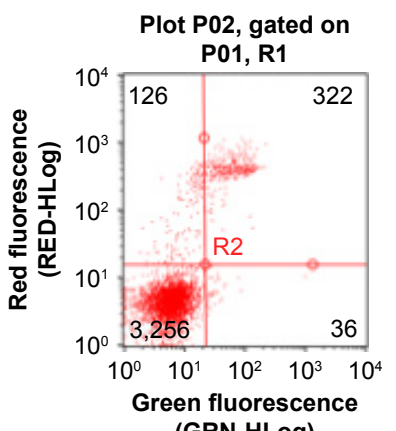

(GRN-HLog)

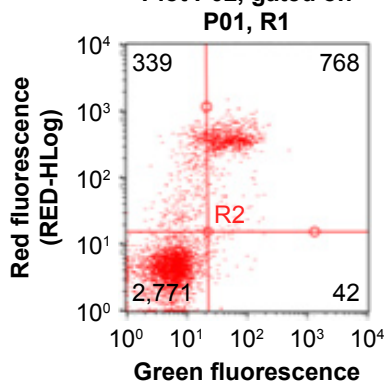

(GRN-HLog)

Plot P02, gated on

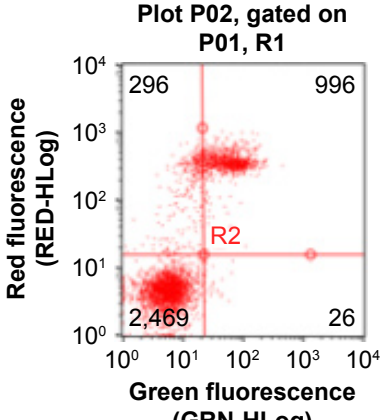

(GRN-HLog)

Notes: $(\mathbf{A})$ The expression of DcR3 in LV-RNAi and LV-NC cell lines was measured by qPCR or ELISA. The differences among cell lines were significant $(P<0.00 \mathrm{I})$. (B) The apoptosis of four different cells (HepG2-NC, HepG2-SiDcR3, BEL-7402-NC, and BEL-7402-SiDcR3) treated with TRAIL (I00 ng/mL) was measured by Annexin V. DMSO was used as control. Data in the bar graphs represent the mean \pm SD of three repeated experiments.

Abbreviations: DcR, decoy receptor; ELISA, enzyme-linked immunosorbent assay; qPCR, quantitative polymerase chain reaction; SD, standard deviation; TRAIL, tumor-necrosis factor-related apoptosis-inducing ligand; DMSO, dimethyl sulfoxide.

absence of caspase- 8 inhibitor (IETD-CHO) and caspase- 9 inhibitor (LEHD-CMK). The activation of caspases-3, -8, and -9 was inhibited obviously in the IETD-CHO group; however, only the activation of caspase- 9 was inhibited in the
LEHD-CMK group. It indicated that caspase-8 activity may play a crucial role in SiDcR3/TRAIL-induced caspase cascade activation. In addition, Western blot (Figure 5) also showed that the antiapoptotic proteins, Bcl-2, Bcl-xl, Mcl-1, IAP-2, 

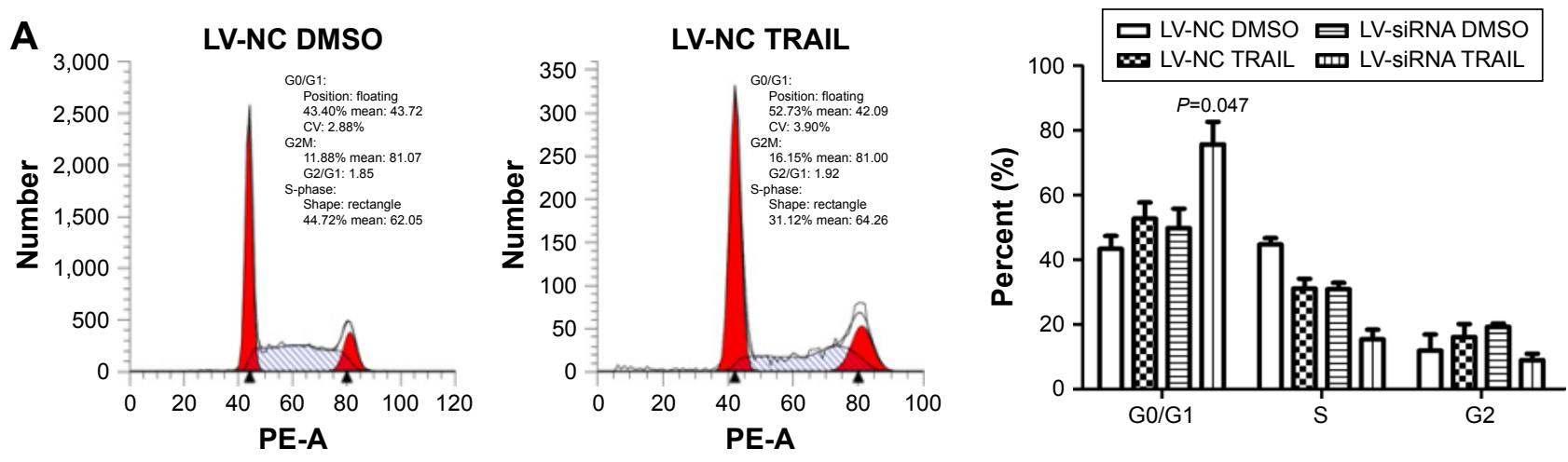

\section{LV-siRNA DMSO}

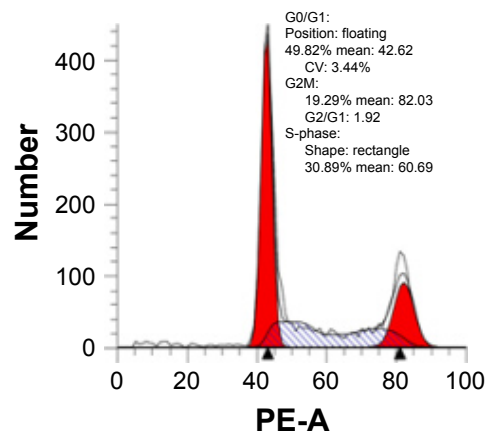

\section{LV-siRNA TRAIL}
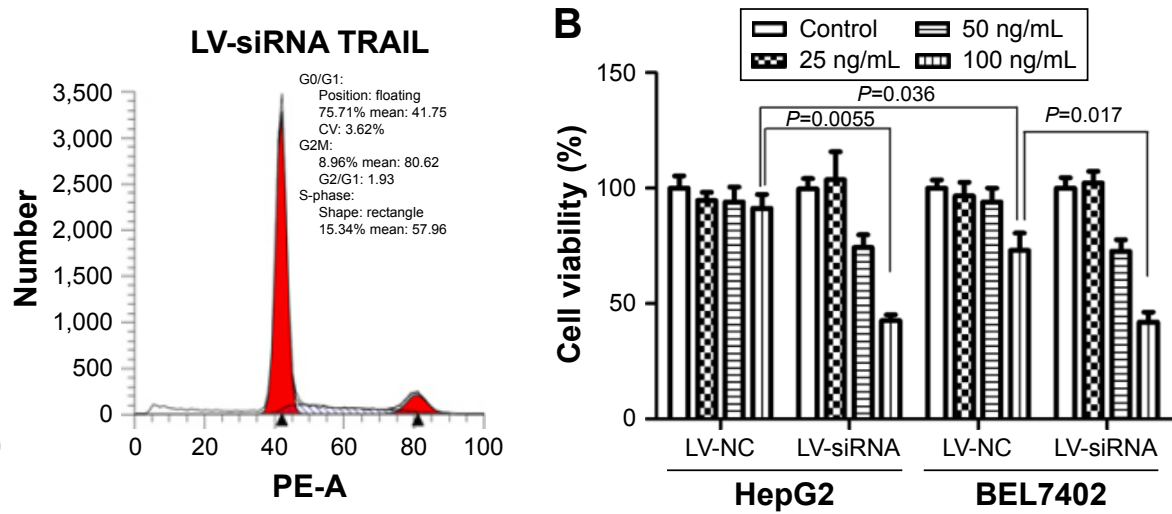

Figure 3 Effect of TRAIL on cell viability and cell cycle.

Notes: (A) Effect of TRAIL on cell cycle of cells in various groups (BEL-7402 LV-NC + DMSO, BEL-7402 LV-NC + TRAIL, BEL-7402 LV-siRNA + DMSO, and BEL-7402 LV-siRNA + TRAIL). The differences among cell lines were significant $(P<0.05)$. The highest percentage of LV-siRNA + TRAIL cells was arrested at G0/GI phase. (B) Effect of TRAIL on cell viability of cells in various groups using CCK-8. The differences among cell lines were significant $(P<0.05)$. All detections were repeated three times and the mean values were used for comparison.

Abbreviations: CCK8, cell counting kit 8; CV, variable coefficient; TRAIL, tumor necrosis factor-related apoptosis-inducing ligand; DMSO, dimethyl sulfoxide.

and survivin were downregulated and that the apoptosispromoting protein Bax was upregulated $(P<0.05)$.

\section{Downregulation of DcR3 combined with TRAIL increased the level of DR5 (TRAIL-R2)}

Previous studies showed that TRAIL receptors DR4 (TRAIL-R1) and DR5 (TRAIL-R2) play a key role in TRAIL resistance in cancer cells. ${ }^{27}$ Therefore, levels of DR4 and DR5 were examined after treatment with TRAIL $(100 \mathrm{ng} / \mathrm{mL})$ for $24 \mathrm{~h}$ in HepG2, HepG2-LV-NC, and HepG2-LV-SiDcR3; DMSO was used as control. As shown in Figure 6A, the level of DR5 was upregulated in HepG2-LV-SiDcR3, while the level of DR4 showed no significant change. In addition, SiDcR3/TRAIL caused a greater increase of DR5 than SiDcR3 or TRAIL alone. Next, we explored whether the upregulation of DR5 was essential. HepG2-LV-SiDcR3 cells were pretreated with neutralizing antibodies to neutralize DR4 and DR5 before treatment with TRAIL (100 ng/mL, incubated for $24 \mathrm{~h}$ ). We found that (Figure 6B) neutralizing DR5 could decrease the apoptosis of HepG2 measured by
Annexin-V/PI assay, but neutralizing DR4 had no obvious effect. In addition, neutralizing DR5 pretreatment could also suppress caspase- 8 activation induced by SiDcR3/TRAIL. These results indicated that downregulation of DcR3 could enhance TRAIL-mediated apoptosis through upregulation of DR5 (TRAIL-R2), and SiDcR3/TRAIL might be a potential method to treat HCC.

\section{Discussion}

DcR3 is expressed highly in a wide variety of tumors such as gastric cancer, ${ }^{28}$ colon cancer, ${ }^{20}$ breast cancer, ${ }^{29}$ bladder cancer, ${ }^{30}$ and liver cancer. ${ }^{31}$ It has been demonstrated that overexpression of DcR3 was correlated with tumor differentiation, lymph node metastasis, as well as TNM stage and prognosis, ${ }^{32}$ while downregulation of DcR3 could inhibit the proliferation and migration of tumor cells and increase the apoptosis of tumor cells. Our previous study ${ }^{33}$ found that the expression of DcR3 in colon cancer cell line SW480 was significantly higher than in normal cells and that the proliferation and migration of colon cancer cells were found to be inhibited when DcR3 was downregulated 
A

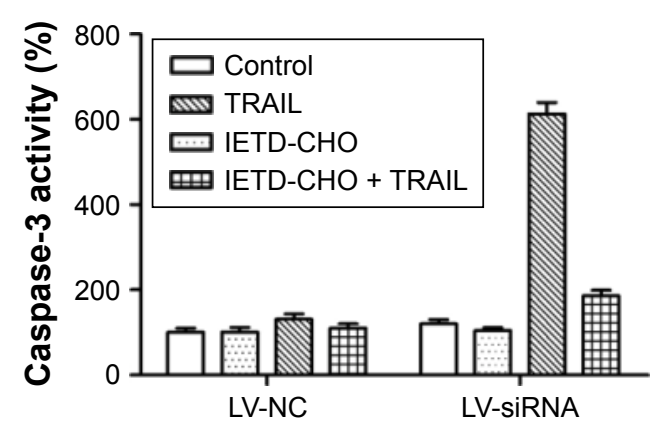

C

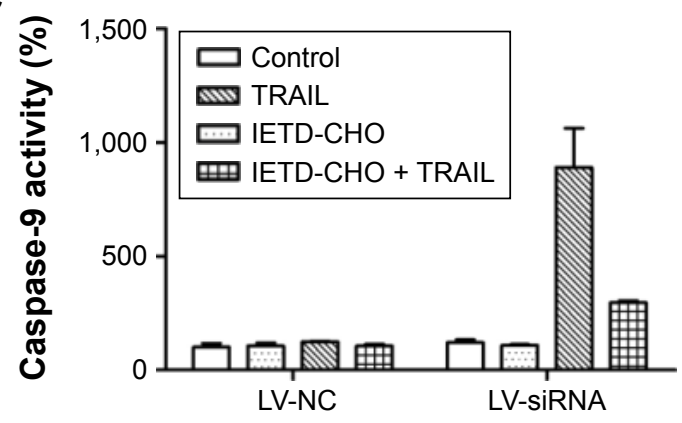

E

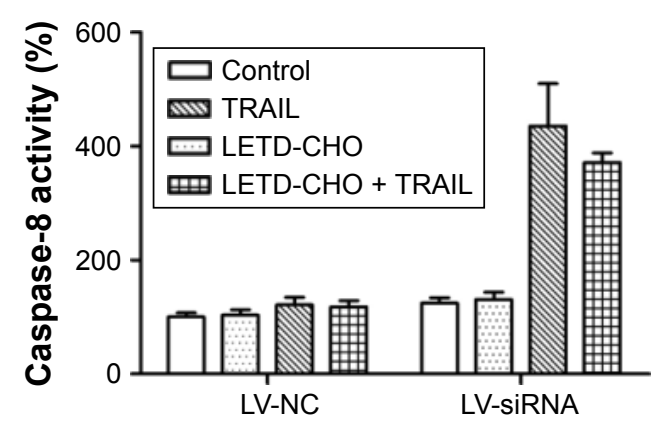

B

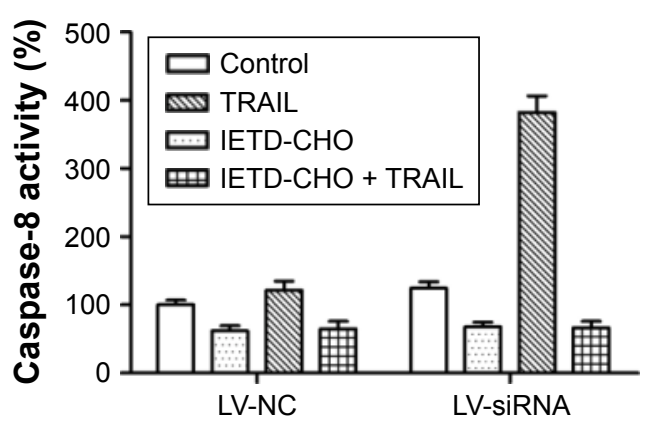

D

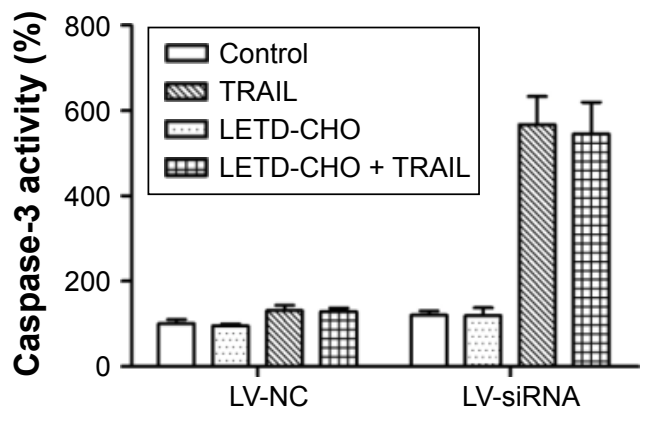

$\mathbf{F}$

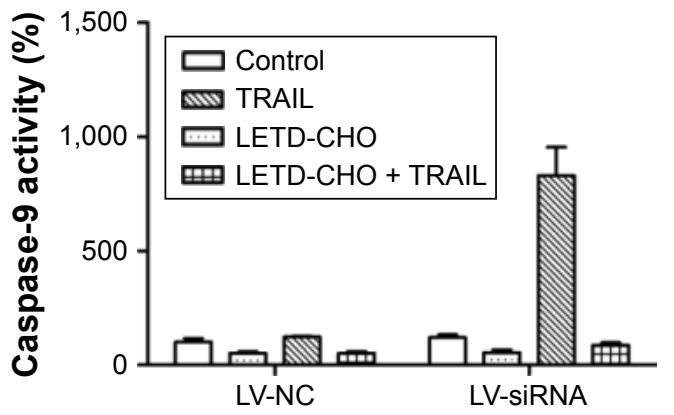

Figure 4 SiDcR3-combined TRAIL activated extrinsic and intrinsic apoptotic signaling pathways.

Notes: (A-F): SiDcR3-combined TRAIL activated extrinsic and intrinsic apoptotic signaling pathways, inhibited caspase-8, and prevented DcR3-TRAlL-induced cascade activation. HepG2 cells were pretreated with $50 \mu$ M Ac-IETD-CHO or $50 \mu$ M Ac-LEHD-CMK 20 min before treatment with TRAIL (I 00 ng/mL, for 24 h). Caspase-3, caspase-8, and caspase-9 activity was determined fluorometrically in cell extracts using Ac-DEVD-AMC, Ac-IETD-AFC, and Ac-LEHD-AMC as flurogenic substrate, respectively.

Abbreviations: DcR, decoy receptor; h, hours; TRAIL, tumor necrosis factor-related apoptosis-inducing ligand.

by siDcR3. In the present study, we demonstrated that the expression of DcR3 in HCC cells was overexpressed compared with normal liver cells. DcR3 has been proven to be one of the ligands binding to FasL. ${ }^{34}$ Further, it was demonstrated that DcR3 regulated the sensitivity of Fas-mediated apoptosis. Zhou et al, ${ }^{24}$ in the study of pancreatic cancer cells, found that the proliferation of pancreatic cell lines Panc-1 and SW1990 was significantly inhibited by SiDcR3 transfection, the sensitivity of cancer cells to Fas-mediated apoptosis was upregulated compared with the control group, and the tumor cells in G0/G1 phase were significantly increased. TRAIL and FasL showed similar findings; some studies ${ }^{25}$ have proven that downregulation of DcR3 in pancreatic cancer cell lines AsPC-1 and MiaPaCa can upregulate the sensitivity of TRAIL-mediated apoptosis and upregulate the apoptotic protein cleaved-PARP. Immunoprecipitation studies have indicated that DcR3 might be a ligand of TRAIL, 25 and so silencing of DcR3 can increase the binding of TRAIL, DR4 (TRAIL-R1), and DR5 (TRAIL-DR5), so as to induce apoptosis. Based on this, we demonstrated that downregulation of DcR3 could sensitize liver cancer cells HepG2 and BEL-7402 to TRAIL-mediated apoptosis, increase HepG2 cells in $\mathrm{G} 0 / \mathrm{G} 1$ phase, and inhibit cell proliferation.

TRAIL, a newly discovered member of the TNF superfamily, is different from TNF and Fas. It only has effects on tumor cell apoptosis and is nontoxic for normal cells. TRAIL can produce strong apoptosis in a wide variety of tumor cells, but Wang et $\mathrm{al}^{26}$ found that almost all of the 
liver cancer cell lines were resistant to TRAIL. Our findings confirmed this as we demonstrated that HepG2 and BEL7402 were tolerant to TRAIL. Further studies on TRAIL resistance have shown that the Bcl-2 family play a crucial role. ${ }^{35} \mathrm{Bcl}-2$ family include three classes: apoptotic proteins
Bax and Bak; prosurvival protein Bcl-2, Bcl-xl, and Mcl-1; and proapoptotic proteins Bid, Bim, Puma, and Noxa. The balance between these proapoptotic and prosurvival proteins regulates apoptosis by controlling the permeability of mitochondrial outer membranes. ${ }^{36}$ Overexpression of

A

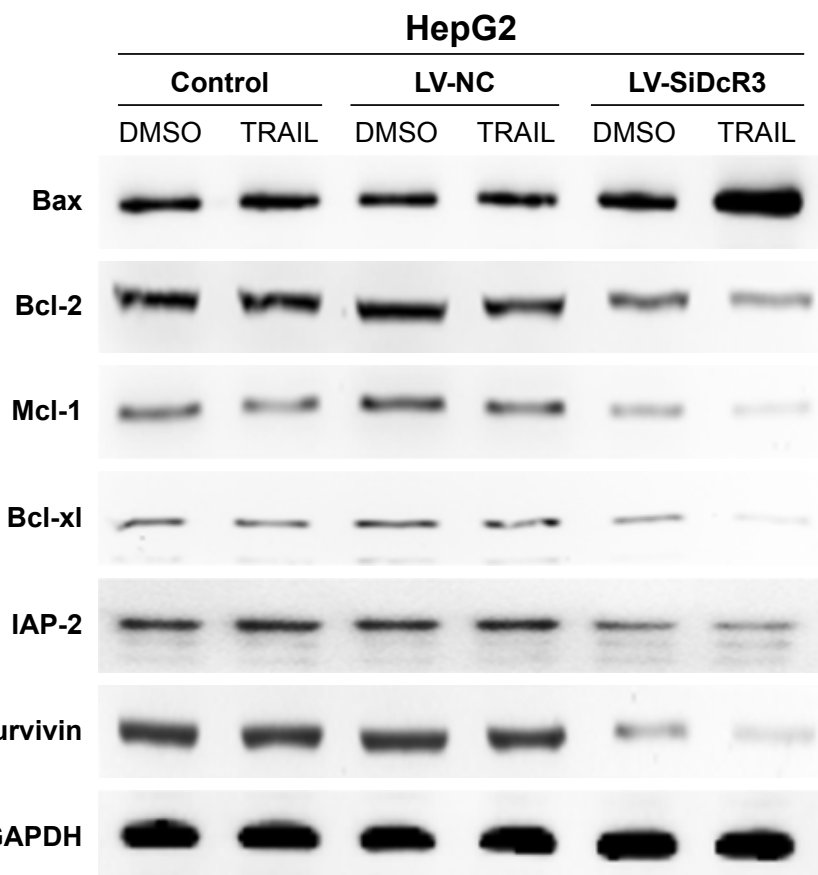

B

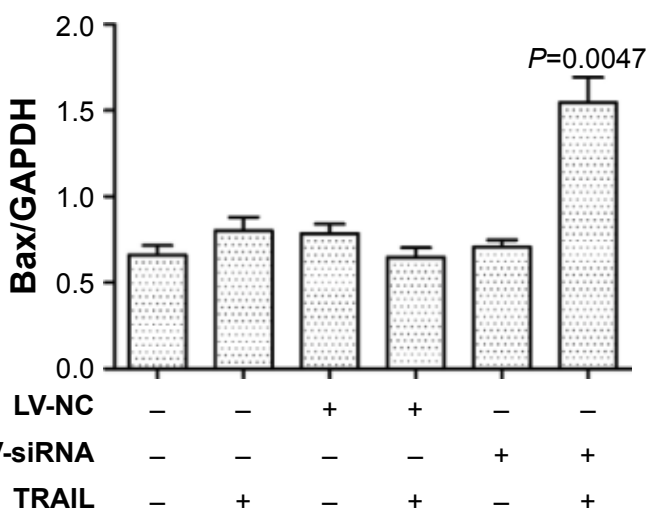

D

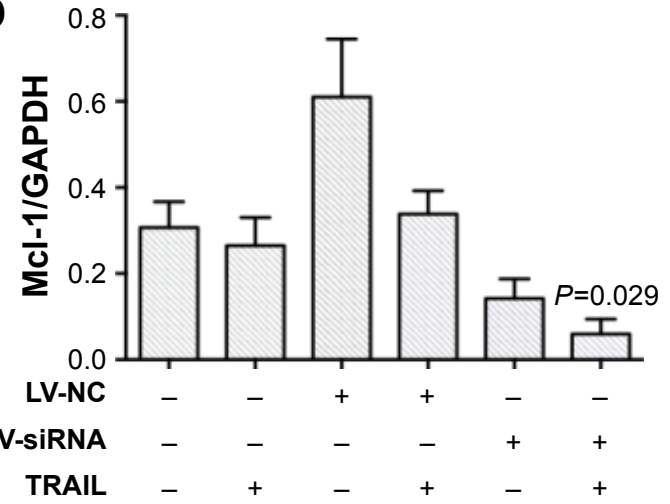

C

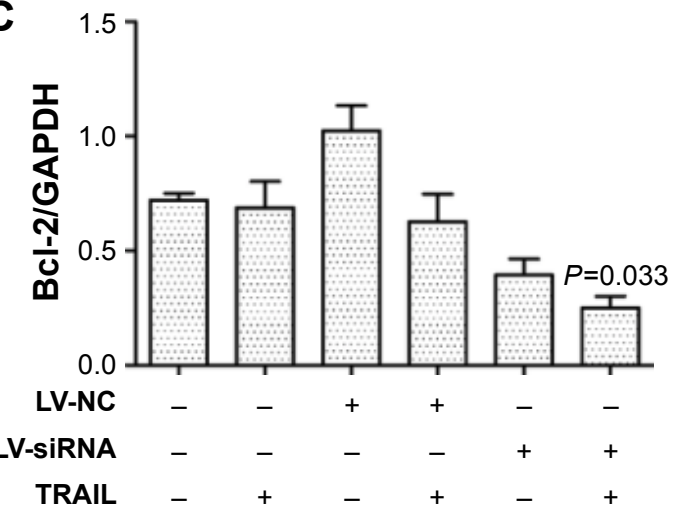

$\mathbf{E}$

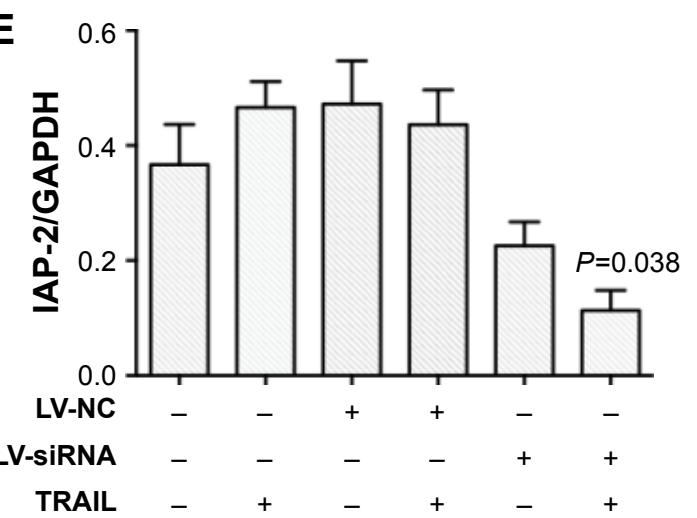

Figure 5 (Continued) 

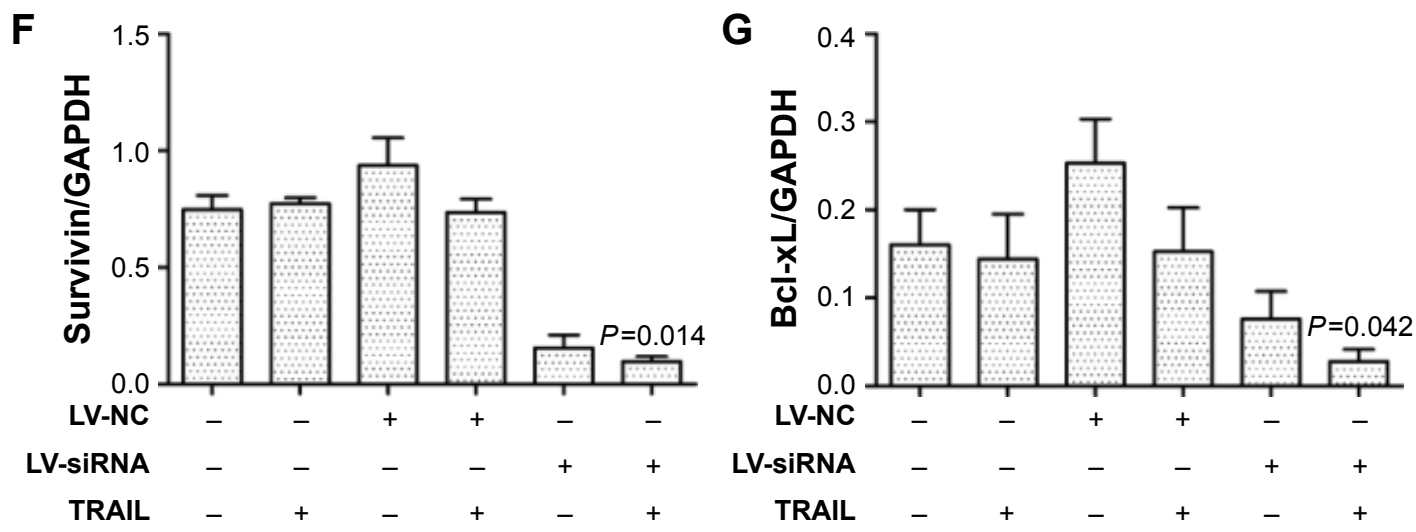

Figure 5 SiDcR3 sensitizes hepatocellular carcinoma cells through Bcl-2 family members.

Notes: (A) The prosurvival Bcl-2 family members Bcl-2, Bcl-xL, IAP-2, survivin, and Mcl-I and proapoptosis member Bax were examined using Western blot analysis after treatment with TRAIL (I00 ng/mL) for 24 h. GAPDH was used as loading control. (B-G) The ratio of each protein to GAPHD. The differences among different proteins were significant $(P<0.05)$. Data in the bar graphs represent the mean $\pm S D$ of three repeated experiments.

Abbreviations: DcR, decoy receptor; h, hours; SD, standard deviation; CV, variable coefficient; TRAIL, tumor necrosis factor-related apoptosis-inducing ligand.

A
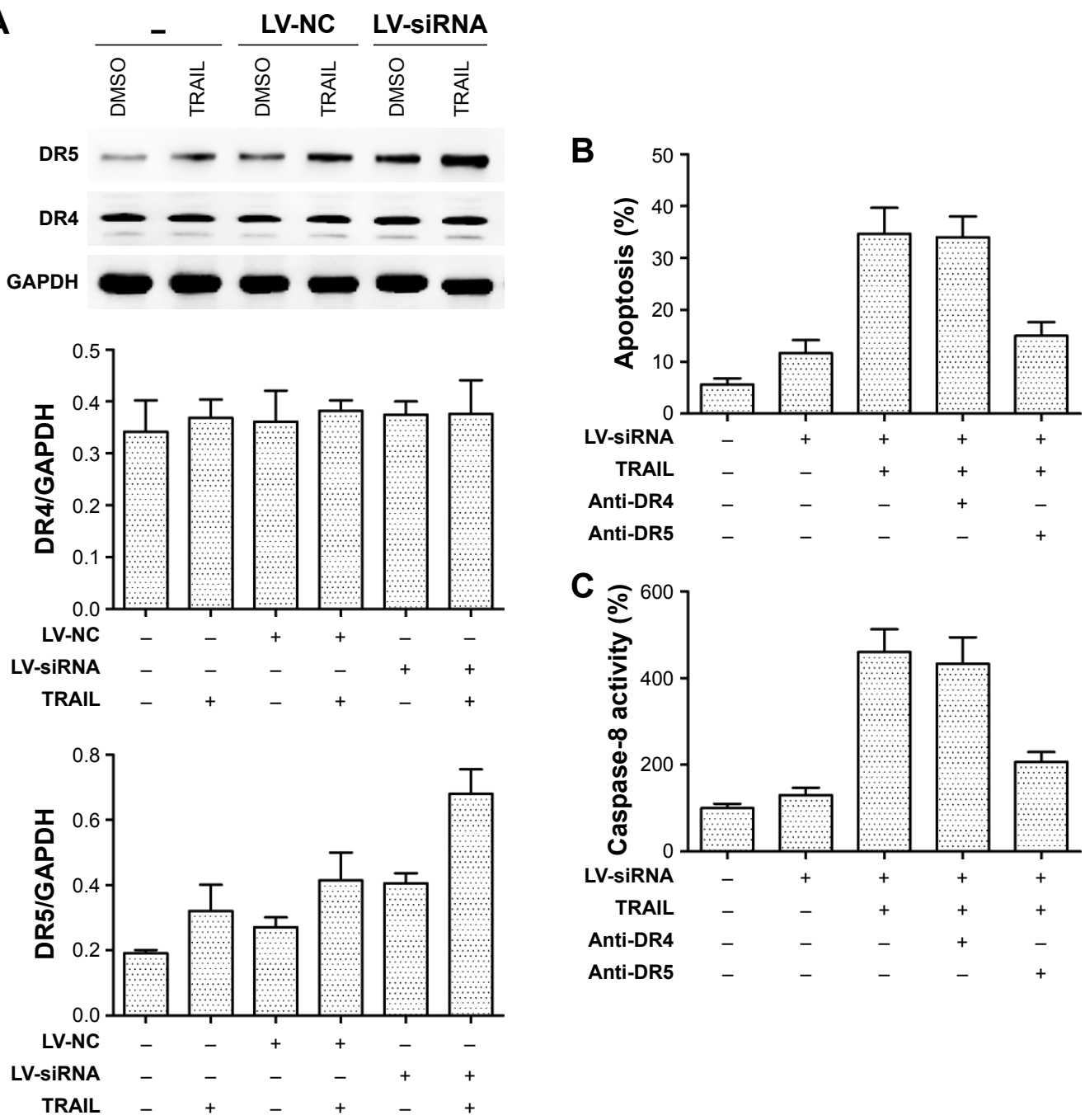

Figure 6 Silencing DcR3 combined TRAIL ( $100 \mathrm{ng} / \mathrm{mL})$ can increase the expression of DR5.

Notes: (A) The expression of DR4 and DR5 was examined by Western blot. GAPHD was used as a loading control. The differences of DR5 among groups were significant $(P<0.00 \mathrm{I})$. (B) HepG2 cells pretreated with neutralizing antibodies against DR4 and DR5 for I h and treated with TRAIL (I00 ng/mL) for $24 \mathrm{~h}$. Apoptosis was analyzed by Annexin-V/PI assay. (C) The caspase-8 activity was determined fluorometrically in cell extracts using Ac-IETD-AFC as the fluorogenic substrate. $P<0.0 \mathrm{I}$. Data in the bar graphs represent the mean \pm SD of three repeated experiments.

Abbreviations: DcR, decoy receptor; h, hours; PI, propidium iodide; SD, standard deviation; TRAIL, tumor necrosis factor-related apoptosis-inducing ligand. 
the antiapoptotic proteins or inhibition of the proapoptotic proteins of Bcl-2 family can result in tumor cell resistance to TRAIL-mediated apoptosis. ${ }^{37-39}$ It has also been shown that inhibition of Bcl-2 proapoptotic members can increase the sensitivity of tumor cells to TRAIL. Our findings indicated that SiDcR3/TRAIL could decrease the expression level of Bcl-2, Bcl-xl, and Mcl-1 and upregulate the level of Bax. IAP protein can inhibit apoptosis through downregulating the catalytic activity of caspase- 3 and caspase- 7 or inhibiting the activity of caspase- 9 in apoptotic bodies. ${ }^{40}$ Overexpression of IAP protein was found in tumor cells that were tolerant to TRAIL-mediated apoptosis, and reduction of IAP-2 could enhance the sensitivity of tumor cells to TRAIL. ${ }^{41,42}$ We found that $\mathrm{SiDcR} 3 / \mathrm{TRAIL}$ could reduce the expression of IAP-2 in HepG2. Similarly, it has been found that overexpression of survivin, a member of the proapoptotic proteins, can also contribute to tumor cell resistance to TRAIL, whereas downregulation of survivin ${ }^{43}$ may increase the sensitivity of tumor cells to TRAIL, and our study showed the same results.

Apoptosis is also called programmed cell death (Figure 7), and normal apoptosis contributes to the balance of the organism. Disorder of apoptosis will lead to the occurrence of tumor, and the anticancer effect of anticancer drugs is mainly through inducing tumor cell apoptosis. ${ }^{44}$ There are two ways to activate apoptosis, ${ }^{45}$ the extrinsic apoptotic pathway (death receptor pathway) and the intrinsic apoptotic pathways (mitochondrial pathway and endoplasmic reticulum pathway). Both of the extrinsic and intrinsic apoptotic pathways are controlled by the activity of caspase. Extrinsic

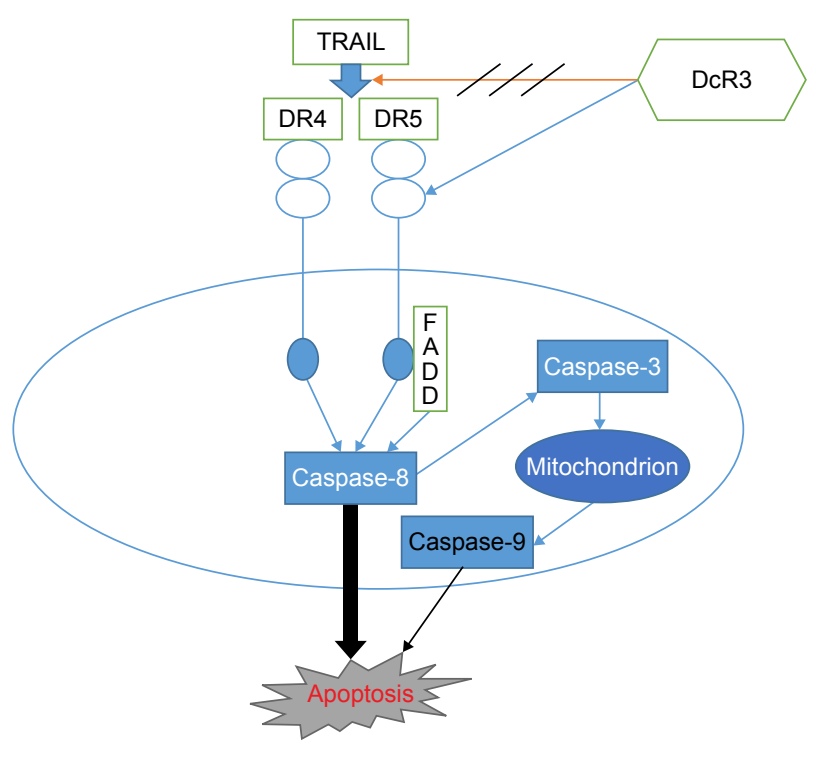

Figure 7 DcR3 and TRAIL-induced apoptosis.

Abbreviations: DcR, decoy receptor; FADD, Fas-associated protein with death domain; TRAIL, tumor necrosis factor-related apoptosis-inducing ligand. pathway is activated through the binding of death receptor and ligand on cell surface, which can produce Fas-associated death domain and activate caspase- 8 , then directly activate caspase-3 or caspase-7, and further activate the intrinsic apoptosis pathway. Studies demonstrated that the activation of caspase- 8 is necessary for the activation of apoptosis, and downregulation or missing of caspase- 8 will contribute to TRAIL resistance. ${ }^{46,47}$ We found that SiDcR3/TRAIL can activate caspase-3, caspase-8, and caspase-9, implying activation of the intrinsic and extrinsic apoptotic pathways in HepG2. Interestingly, when caspase-8 inhibitor IETD-CHO was used in the treatment, the apoptosis of HCC decreased significantly, which indicated that this specific apoptosis was mainly through death receptor pathway dependent on caspase-8.

DR4 and DR5 are receptors of TRAIL, and binding of TRAIL and DR4 or DR5 can induce apoptosis by formation of a polymer. Previous studies found that missing DR4 or DR5 in tumor cells contributed to the resistance to TRAIL, ${ }^{48}$ and increasing the expression of DR4/DR5 could enhance TRAIL-mediated apoptosis in tumor cells. ${ }^{49}$ Weissinger et $\mathrm{al}^{50}$ found that DcR3 promoted adhesion, migration, and invasiveness in RCC cells, indicating that the expression of DcR3 could be regulated by $\mathrm{PI} 3 \mathrm{~K} / \mathrm{AKT}$, NFAT, and SP-1, and inhibiting of DFAT and SP-1 could decrease the expression of DcR3. Yoshida and Sakai ${ }^{51}$ demonstrated that SP1 could increase the expression of DR5 (TRAIL-R2), but that other members of TNFR showed no change, which suggested that DR5 might be related to DcR3. We first found that SiDcR3 in HepG2 could increase the level of DR5; later, when we incubated the cells with DR5 neutralizing antibodies, the apoptosis decreased obviously, and the activity of caspase- 8 declined at the same time. These findings confirmed that SiDcR3 enhanced TRAIL-mediated apoptosis by increasing DR5 level.

A previous study ${ }^{52}$ has found that upregulation of DcR3 enhances the sensitivity of TRAIL-mediated apoptosis and increases the level of DR5. Unexpectedly, our findings were the opposite. A possible reason is that the findings are associated with cell types, which illustrated the difference between normal cells and tumor cells. Without doubt, this needs further validation.

\section{Conclusion}

In summary, SiDcR3 in HepG2 could enhance the sensitivity of TRAIL-mediated apoptosis through upregulation of DR5, and this may provide a theoretical basis for developing new treatment for liver cancer. 


\section{Acknowledgments}

This study was funded by the National Natural Science Foundation of China (81550033), Beijing Municipal Administration of Hospital Clinical Medicine Development of Special Funding Support (ZYLX201612), Capital Foundation of Medical Development (shoufa2016-2-2053), Beijing Tongren Hospital Funds (TRYY-KYJJ-2015-032).

\section{Disclosure}

The authors report no conflicts of interest in this work.

\section{References}

1. Marquardt JU, Thorgeirsson SS. SnapShot: hepatocellular carcinoma. Cancer Cell. 2014;25(4):550.e551.

2. Siegel R, Naishadham D, Jemal A. Cancer statistics, 2012. CA Cancer J Clin. 2012;62(1):10-29.

3. Llovet JM, Burroughs A, Bruix J. Hepatocellular carcinoma. Lancet. 2003;362(9399):1907-1917.

4. Avila MA, Berasain C, Sangro B, Prieto J. New therapies for hepatocellular carcinoma. Oncogene. 2006;25(27):3866-3884.

5. Del Pozo AC, Lopez P. Management of hepatocellular carcinoma. Clin Liver Dis. 2007;11(2):305-321.

6. Wiley SR, Schooley K, Smolak PJ, et al. Identification and characterization of a new member of the TNF family that induces apoptosis Immunity. 1995;3(6):673-682.

7. Pitti RM, Marsters SA, Ruppert S, Donahue CJ, Moore A, Ashkenazi A. Induction of apoptosis by Apo-2 ligand, a new member of the tumor necrosis factor cytokine family. $J$ Biol Chem. 1996;271(22):12687-12690.

8. Golstein P. Cell death: TRAIL and its receptors. Curr Biol. 1997;7(12): R750-R753.

9. Wu GS, Burns TF, McDonald ER 3rd, et al. KILLER/DR5 is a DNA damage-inducible p53-regulated death receptor gene. Nat Genet. 1997; 17(2):141-143.

10. Sheridan JP, Marsters SA, Pitti RM, et al. Control of TRAIL-induced apoptosis by a family of signaling and decoy receptors. Science. 1997; 277(5327):818-821.

11. Kischkel FC, Lawrence DA, Chuntharapai A, Schow P, Kim KJ, Ashkenazi A. Apo2L/TRAIL-dependent recruitment of endogenous FADD and caspase-8 to death receptors 4 and 5. Immunity. 2000;12(6): 611-620.

12. Sprick MR, Weigand MA, Rieser E, et al. FADD/MORT1 and caspase- 8 are recruited to TRAIL receptors 1 and 2 and are essential for apoptosis mediated by TRAIL receptor 2. Immunity. 2000;12(6):599-609.

13. Enari M, Talanian RV, Wong WW, Nagata S. Sequential activation of ICE-like and CPP32-like proteases during Fas-mediated apoptosis. Nature. 1996;380(6576):72-726.

14. Hall MA, Cleveland JL. Clearing the TRAIL for cancer therapy. Cancer Cell. 2007;12(1):4-6.

15. Zhang JS, Herreros-Villanueva M, Koenig A, et al. Differential activity of GSK-3 isoforms regulates NF-kappaB and TRAIL- or TNFalpha induced apoptosis in pancreatic cancer cells. Cell Death Dis. 2014;5:e1142.

16. Omar HA, Arafa el SA, Maghrabi IA, Weng JR. Sensitization of hepatocellular carcinoma cells to Apo2L/TRAIL by a novel Akt/NFkappaB signalling inhibitor. Basic Clin Pharmacol Toxicol. 2014; 114(6):464-471.

17. Tsuji S, Hosotani R, Yonehara S, et al. Endogenous decoy receptor 3 blocks the growth inhibition signals mediated by Fas ligand in human pancreatic adenocarcinoma. Int J Cancer. 2003;106(1):17-25.

18. Yu KY, Kwon B, Ni J, Zhai Y, Ebner R, Kwon BS. A newly identified member of tumor necrosis factor receptor superfamily (TR6) suppresses LIGHT-mediated apoptosis. J Biol Chem. 1999;274(20):13733-13736.
19. Takahashi M, Miura Y, Hayashi S, Tateishi K, Fukuda K, Kurosaka M. DcR3-TL1A signalling inhibits cytokine-induced proliferation of rheumatoid synovial fibroblasts. Int J Mol Med. 2011;28(3):423-427.

20. Liang QL, Wang BR, Li GH. DcR3 and survivin are highly expressed in colorectal carcinoma and closely correlated to its clinicopathologic parameters. J Zhejiang Univ Sci B. 2009;10(9):675-682.

21. Wang W, Li X, Sun W, et al. Triptolide triggers the apoptosis of pancreatic cancer cells via the downregulation of Decoy receptor 3 expression. J Cancer Res Clin Oncol. 2012;138(9):1597-1605.

22. Sung HY, Wu HG, Ahn JH, Park WY. Dcr3 inhibit p53-dependent apoptosis in gamma-irradiated lung cancer cells. Int J Radiat Biol. 2010; 86(9):780-790.

23. Yang D, Fan X, Yin P, et al. Significance of decoy receptor 3 (Dcr3) and external-signal regulated kinase $1 / 2($ Erk1/2) in gastric cancer. $B M C$ Immunol. 2012;13:28.

24. Zhou J, Song S, He S, et al. Silencing of decoy receptor 3 (DcR3) expression by siRNA in pancreatic carcinoma cells induces Fas ligand-mediated apoptosis in vitro and in vivo. Int J Mol Med. 2013;32(3):653-660.

25. Wang W, Zhang M, Sun W, et al. Reduction of decoy receptor 3 enhances TRAIL-mediated apoptosis in pancreatic cancer. PLoS One. 2013; 8(10): 74272.

26. Wang G, Zhan Y, Wang H, Li W. ABT-263 sensitizes TRAIL-resistant hepatocarcinoma cells by downregulating the Bcl-2 family of anti-apoptotic protein. Cancer Chemother Pharmacol. 2012;69(3):799-805.

27. Takeda K, Stagg J, Yagita H, Okumura K, Smyth MJ. Targeting death-inducing receptors in cancer therapy. Oncogene. 2007;26(25): $3745-3757$.

28. Wu Y, Guo E, Yu J, Xie Q. High DcR3 expression predicts stage pN2-3 in gastric cancer. Am J Clin Oncol. 2008;31(1):79-83.

29. Wu Q, Zheng Y, Chen D, Li X, Lu C, Zhang Z. Aberrant expression of decoy receptor 3 in human breast cancer: relevance to lymphangiogenesis. J Surg Res. 2014;188(2):459-465.

30. Jiang YQ, Zhong TF, Dang YW, et al. Overexpression and clinicopathological contribution of DcR3 in bladder urothelial carcinoma tissues. Asian Pac J Cancer Prev. 2014;15(21):9137-9142.

31. Chen C, Zhang C, Zhuang G, et al. Decoy receptor 3 overexpression and immunologic tolerance in hepatocellular carcinoma (HCC) development. Cancer Invest. 2008;26(10):965-974.

32. Tong J, Ao R, Wang Y, Chang B, Wang BY. Prognostic and clinicopathological differences of DcR3 in gastrointestinal cancer: evidence from meta-analysis. Int J Clin Exp Med. 2014;7(9):3096-3105.

33. Yu W, Xu YC, Tao Y, et al. DcR3 regulates the growth and metastatic potential of SW480 colon cancer cells. Oncol Rep. 2013;30(6): 2741-2748.

34. Pitti RM, Marsters SA, Lawrence DA, et al. Genomic amplification of a decoy receptor for Fas ligand in lung and colon cancer. Nature. 1998; 396(6712):699-703.

35. Youle RJ, Strasser A. The BCL-2 protein family: opposing activities that mediate cell death. Nat Rev Mol Cell Biol. 2008;9(1):47-59.

36. Shamas-Din A, Kale J, Leber B, Andrews DW. Mechanisms of action of Bcl-2 family proteins. Cold Spring Harb Perspect Biol. 2013;5(4): a008714.

37. Indran IR, Tufo G, Pervaiz S, Brenner C. Recent advances in apoptosis, mitochondria and drug resistance in cancer cells. Biochim Biophys Acta. 2011;1807(6):735-745.

38. LeBlanc H, Lawrence D, Varfolomeev E, et al. Tumor-cell resistance to death receptor - induced apoptosis through mutational inactivation of the proapoptotic Bcl-2 homolog Bax. Nat Med. 2002;8(3):274-281.

39. Hinz S, Trauzold A, Boenicke L, et al. Bcl-XL protects pancreatic adenocarcinoma cells against CD95- and TRAIL-receptor-mediated apoptosis. Oncogene. 2000;19(48):5477-5486.

40. Zhang L, Fang B. Mechanisms of resistance to TRAIL-induced apoptosis in cancer. Cancer Gene Ther. 2005;12(3):228-237.

41. Ng CP, Zisman A, Bonavida B. Synergy is achieved by complementation with Apo2L/TRAIL and actinomycin D in Apo2L/TRAIL-mediated apoptosis of prostate cancer cells: role of XIAP in resistance. Prostate. 2002;53(4):286-299. 
42. Jung YH, Lim EJ, Heo J, Kwon TK, Kim YH. Tunicamycin sensitizes human prostate cells to TRAIL-induced apoptosis by upregulation of TRAIL receptors and downregulation of cIAP2. Int J Oncol. 2012;40(6): 1941-1948.

43. Han Z, Lee S, Je S, et al. Survivin silencing and TRAIL expression using oncolytic adenovirus increase anti-tumorigenic activity in gemcitabineresistant pancreatic cancer cells. Apoptosis. 2016;21(3):351-364.

44. Fesik SW. Promoting apoptosis as a strategy for cancer drug discovery. Nat Rev Cancer. 2005;5(11):876-885.

45. Moffitt KL, Martin SL, Walker B. From sentencing to execution - the processes of apoptosis. J Pharm Pharmacol. 2010;62(5):547-562.

46. Bodmer JL, Holler N, Reynard S, et al. TRAIL receptor-2 signals apoptosis through FADD and caspase-8. Nat Cell Biol. 2000;2(4):241-243.

47. Seol DW, Li J, Seol MH, Park SY, Talanian RV, Billiar TR. Signaling events triggered by tumor necrosis factor-related apoptosis-inducing ligand (TRAIL): caspase-8 is required for TRAIL-induced apoptosis. Cancer Res. 2001;61(3):1138-1143.
48. Zhang Y, Zhang B. TRAIL resistance of breast cancer cells is associated with constitutive endocytosis of death receptors 4 and 5. Mol Cancer Res. 2008;6(12):1861-1871.

49. Gupta SC, Reuter S, Phromnoi K, et al. Nimbolide sensitizes human colon cancer cells to TRAIL through reactive oxygen species- and ERK-dependent up-regulation of death receptors, p53, and Bax. J Biol Chem. 2011;286(2):1134-1146.

50. Weissinger D, Tagscherer KE, Macher-Goppinger S, Haferkamp A, Wagener N, Roth W. The soluble Decoy Receptor 3 is regulated by a $\mathrm{PI} 3 \mathrm{~K}$-dependent mechanism and promotes migration and invasion in renal cell carcinoma. Mol Cancer. 2013;12(1):120.

51. Yoshida T, Sakai T. Promoter of TRAIL-R2 gene. Vitam Horm. 2004; 67:35-49.

52. You RI, Chang YC, Chen PM, et al. Apoptosis of dendritic cells induced by decoy receptor 3 (DcR3). Blood. 2008;111(3):1480-1488.
OncoTargets and Therapy

\section{Publish your work in this journal}

OncoTargets and Therapy is an international, peer-reviewed, open access journal focusing on the pathological basis of all cancers, potential targets for therapy and treatment protocols employed to improve the management of cancer patients. The journal also focuses on the impact of management programs and new therapeutic agents and protocols on

\section{Dovepress}

patient perspectives such as quality of life, adherence and satisfaction. The manuscript management system is completely online and includes a very quick and fair peer-review system, which is all easy to use. Visit http://www.dovepress.com/testimonials.php to read real quotes from published authors. 